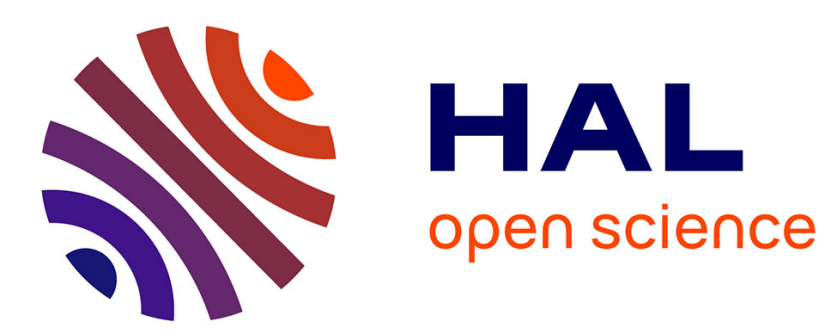

\title{
Thin-film adhesion: a comparative study between colored picosecond acoustics and spontaneous buckles analysis
}

\author{
Arnaud Devos, A. Vital-Juarez, A. Chargui, M.J. Cordill
}

\section{To cite this version:}

Arnaud Devos, A. Vital-Juarez, A. Chargui, M.J. Cordill. Thin-film adhesion: a comparative study between colored picosecond acoustics and spontaneous buckles analysis. Surface and Coatings Technology, 2021, 421, pp.127485. 10.1016/j.surfcoat.2021.127485 . hal-03282288

\section{HAL Id: hal-03282288 \\ https://hal.science/hal-03282288}

Submitted on 3 Sep 2021

HAL is a multi-disciplinary open access archive for the deposit and dissemination of scientific research documents, whether they are published or not. The documents may come from teaching and research institutions in France or abroad, or from public or private research centers.
L'archive ouverte pluridisciplinaire HAL, est destinée au dépôt et à la diffusion de documents scientifiques de niveau recherche, publiés ou non, émanant des établissements d'enseignement et de recherche français ou étrangers, des laboratoires publics ou privés. 
1 Thin-film Adhesion: A Comparative Study Between Colored Picosecond Acoustics and

2 Spontaneous Buckles Analysis

3

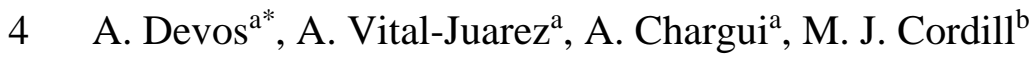

5 a IEMN - UMR8250 CNRS - Avenue Poincaré BP 69 - 59652 Villeneuve d'Ascq cedex -

6 France

$7{ }^{\mathrm{b}}$ Erich Schmid Institute of Materials Science, Austrian Academy of Sciences, Jahnstrasse 12, $8 \quad 8700$ Leoben, Austria

9

Abstract

This paper presents some quantitative measurements of the adhesion energy of thin WTi films deposited on Si substrate. Two different techniques are applied to the same sample series. One is a mechanical test based on the analysis of spontaneously formed defects. The second is based on acoustic waves whose reflection at the interface between the thin-film and the substrate is sensitive to the adhesion. An excellent correlation is obtained between both approaches: the adhesion energy measured by buckles analysis and acoustic reflection coefficient measured by picosecond acoustics. The acoustic approach offers several advantages among which a nondestructive character, a compatibility with complex stacks and a sensitivity to detect adhesion anomaly even if no defect is formed.

21 Keywords: adhesion; thin film; buckles; reflection coefficient; picosecond acoustics.

\footnotetext{
* Corresponding author: Arnaud.Devos@iemn.fr, tel +33.359574402, fax +33.320304051, IEMN Dpt ISEN, 41 Bd Vauban, 59046 Lille cedex - France
} 


\section{1. Introduction}

2 Industry and especially microelectronics push towards the nanoscale by fabricating devices

3 based on more and more complex stacks of thin films in which are mixed heterogeneous

4 materials. For example, a radio-frequency filter in a mobile phone is built on several resonators

5 each of them being made of more than 15 layers stacked together. Metals, dielectrics and

6 semiconductors are mixed together in a very complex multilayer and adhesion becomes a

7 crucial issue for device reliability [1]-[4].

8 Numerous methods have been proposed to test adhesion [5]-[7] (either in a qualitative manner

9 (yes/no test, like tape test [8]) or quantitatively by measuring an adhesion energy at the specific 10 interface, for example scratch testing [9][10], four point bend testing [11][12] stressed 11 overlayers [13]-[15], and nanoindentation [16]-[18]. While these approaches are well-known 12 and successfully measure adhesion energies, a requirement of all of the methods is delamination 13 of the interface must occur. Thus, the methods are destructive and not always compatible with 14 complex material stacks. For the four point bending method, multi-layer stacks can be 15 evaluated, but require a sandwich sample geometry that can be difficult to make and only the 16 weakest interface can be measured. Stressed overlayers are often limited as well and can be 17 combined with nanoindentation and scratch methods [18]. Nanoindentation and scratch methods require access to proper instrumentation and also is somewhat a trial and error process to induce delamination of the desired interface. A non-destructive method that can also be used to quantify the adhesion energy of multiple interfaces would be useful for hard to delaminate

21 interfaces.

22 Acoustic waves can also be used to investigate adhesion and, more importantly, in a nondestructive manner. For more than 30 years, picosecond acoustics (PA) has opened the field of

24 thin and ultra-thin layers to acoustics [19]. Similar to a sonar but at the nanoscale and based on ultrafast laser pulses, PA has found many applications especially to the thickness control of 
1 complex stacks [20][21]. It has also been proposed as a tool for detecting adhesion defects [22].

2 Indeed, a poor adhesion affects the reflection of acoustic waves at the concerned interface so

3 that by measuring the reflection coefficient one can rank samples or compare places along the

4 sample surface from the adhesion point of view.

5 To go further one needs to have a direct comparison between the acoustic adhesion number

6 (namely the reflection coefficient) and the adhesion energy measured with a mechanical model.

7 In this paper we apply two much different adhesion techniques to a same set of samples: one is

8 a variant of PA designed in the following as Colored Picosecond Acoustics (APiC) [23]; one is

9 a mechanical adhesion measurement based on an analysis of buckles defects that appear

10 spontaneously on the sample surface. From such a comparison, we demonstrate that APiC

11 technique can provide semi-quantitative adhesion measurements that are local and non-

12 destructive.

13

14 2. Experimental details

15 2.1. Samples description

16 The study is performed on a series of three similar WTi films with approximately $20 \% \mathrm{Ti}$

17 content and that were sputter deposited using a single WTi target in industrial sputtering

18 machine to a thickness of $250 \mathrm{~nm}$. The films were sputtered onto Si substrates with a native

$19 \mathrm{SiO}_{2}$ oxide of a few nanometers (approximately 2-5 $\mathrm{nm}$ ). Due to the high compressive residual

20 stress, all films spontaneously delaminated forming the well-known telephone cord buckle

21 shape. Such defects are used to deduce the adhesion energy of the WTi layer on the Si substrate

22 following the pioneered work of Hutchinson and Suo [24].

24 2.2. Measuring adhesion energy using buckles 
1 Confocal laser scanning microscopy (CLSM, Olympus LEXT 4100 OLS) was used to image

2 the buckles for further analysis. CLSM uses a laser and precise stage movement to create laser

3 intensity images, quantitative height images, and focused resolved optical light images. From

4 the height images, (Figure 1 a-c) the buckle heights, $\delta$, and buckle widths, $2 b$, can be measured

5 (Figure 1d). The buckle dimensions with the film thickness, $h$, and elastic properties (Young's

6 Modulus $E$, Poisson ratio $v$ ) of the film were then used to calculate the critical buckling stress,

$7 \sigma_{b}$, and the driving stress, $\sigma_{d}$ (Eqn. 1 and 2) following the model of Hutchinson and Suo [24],

10

$$
\sigma_{b}=\frac{\pi^{2} E}{12\left(1-v^{2}\right)}\left(\frac{h}{b}\right)^{2}
$$

For WTi, $E=322 \mathrm{GPa}$ was measured using nanoindentation with a Berkovich tip $(R=150$ $\mathrm{nm})$ and $v=0.288$ was determined with a rule of mixtures [25]. Indents were performed using the full available load range of a Hysitron TriboScope Nanoindenter, namely $100 \mu \mathrm{N}$ to $10,000 \mu \mathrm{N}$, which corresponds to depths between $50 \mathrm{~nm}$ and $450 \mathrm{~nm}$. Then the measured stiffness versus the contact depths were plotted and described with the model from Li and Vlassak [26] to reach the 322 GPa elastic modulus for the WTi. From the calculated stresses, the mixed mode adhesion energy, $\Gamma(\Psi)$, was determined with Eqn. 3,

$$
\Gamma(\Psi)=\left[\frac{\left(1-v^{2}\right) h}{2 E}\right]\left(\sigma_{d}-\sigma_{b}\right)\left(\sigma_{d}+3 \sigma_{b}\right),
$$

where $\Psi$ is the phase angle of loading.

It should be noted that the Hutchinson and Suo model is for straight-sided buckles and not telephone cord shaped buckles. While several groups have provided new adhesion models for telephone cord buckles [12] [27] [28], it is still acceptable to use the Hutchinson and Suo model for telephone cord buckles, especially when the buckle dimensions are measured at the point of inflection as demonstrated in Figure 1b. At this point the buckle cross-section is symmetric and can be modeled as a straight-sided buckle [28]. 
2 2.3. APiC experimental details

3 Basically, APiC is an ultrafast laser technology that implements a pulse-echo technique at the

4 nanoscale [29]. The light absorption of a first laser light pulse (the pump) leads to the emission

5 of a short acoustic pulse. It propagates in the film at the sound velocity and is partially reflected

6 toward the surface when it reaches the film/substrate interface. The returning echo is optically

7 detected using another laser pulse (the probe) time-delayed with respect to the pump pulse.

8 By detecting successive acoustic echoes, one can first measure the time-of-flight and deduce

9 the film thickness from the longitudinal sound velocity. A schematic view of the experimental setup is given in Fig. 2. From the successive echo amplitude, one extracts the acoustic reflection

11 coefficient. The portion of the strain pulse that is reflected at an interface is governed by the

12 ratio between the acoustic impedances of both materials. The acoustic impedance of a given material $(Z)$ is the product of the mass density by the sound velocity. And when an acoustic wave reaches an interface, the expected reflection coefficient is given by:

$$
R=\frac{\left(Z_{2}-Z_{1}\right)}{\left(Z_{2}+Z_{1}\right)}
$$

where $R$ is the reflection coefficient, and $Z_{1}$ and $Z_{2}$ are the respective acoustic impedances of the two materials [22].

In the present case, the WTi material has a very high acoustic impedance compared to silicon which means that a significant part of the acoustic pulse is reflected at the interface with the substrate. Assuming a sound velocity of $5350 \mathrm{~m} / \mathrm{s}$ and a mass density of $15.3 \mathrm{~g} . \mathrm{cm}^{-3}$, one obtains

$21 Z_{1}=81.910^{6} \mathrm{~kg} \cdot \mathrm{m}^{-2} \mathrm{~s}^{-1}$ and $R=-0,61$ at the interface with a Si substrate $\left(Z_{2}=19.710^{6} \mathrm{~kg} \cdot \mathrm{m}^{-2} \mathrm{~s}^{-1}\right)$. The negative sign is related to the fact that the second medium has a lower impedance than the

23 first one. In the following we ignore the sign of $R$ and only focus on its magnitude $|R|$. The 24 poorer the adhesion is, the higher $|R|$ will be. The extreme case is a total delamination, then the degree of reflection is close to -1 . 
1 Experimentally, APiC measurements were carried on using a commercial tunable Ti:Sapphire

2 oscillator and a conventional pump and probe scheme at normal incidence. The laser produces

$3120 \mathrm{fs}$ optical pulses at a repetition rate of $80 \mathrm{MHz}$ tunable between 690 and $1050 \mathrm{~nm}$ [30].

4 Using second harmonic generation in a $\beta-\mathrm{BaB}_{2} \mathrm{O}_{4}$ crystal, blue laser beam is generated to serve

5 as a probe which is time-delayed with respect to the pump using a mechanical delay line. Both

6 pump and probe beams are focused on the same point at the sample surface using a microscope

7 objective $\mathrm{x} 20$. The ratio between the pump and probe intensities is close to 1000:1. To improve

8 the signal-to-noise ratio, the pump beam is chopped using an acousto-optic modulator and the

9 output of the photodiode, which monitors the reflected probe, is amplified through a lock-in

10 scheme.

11 The focused spot size at the sample surface is close to $1-2 \mu \mathrm{m}$ in diameter which means that

12 APiC measurement is made locally. The sample is fixed on a $100 \mathrm{~mm} \mathrm{XY}$ translation stage 13 which offers the opportunity to control the place where the measurement is performed. This way complete mapping the sample response can be obtained with a XY resolution better than $0.5 \mu \mathrm{m}$ along surfaces as large as $100 \mathrm{~mm} \times 100 \mathrm{~mm}$.

\section{Results and discussion}

3.1. Adhesion from defect analysis results

In order to evaluate the interface adhesion energy, at least 30 measurements of buckles were made on each WTi sample. Table I summarizes the adhesion results and illustrates that Sample WTi-3 had a slightly higher adhesion compared to Samples WTi-1 and WTi-2. The values are also similar to previous studies of WTi films on Si and dielectric films [31] [32]. The differences in the mixed mode adhesion energies between the three samples can be considered small. WTi-1 and WTi-2 are quite close and when the standard deviations are taken into account, all values overlap. A possible reason for WTi-3 to have a slightly larger adhesion 
1 energy is that this sample came from a different radius on the wafer, for example closer to the

2 wafer edge, where the average buckle dimensions (Table I) are slightly smaller, leading to the

3 higher adhesion energies.

\subsection{APiC results}

6 Figure 2 presents the transient reflectivity measured on the three WTi samples. A sudden change in the reflectivity is visible at $\mathrm{t}=0$. At such a time-delay, the pump laser is exciting the thin metallic film. Light is first absorbed by electrons in the metal which leads to strong change in the optical reflectivity. About 1 ps later photoexcited electrons go back to their original states transferring the excess of energy to the lattice as heat and the reflectivity goes down. The very

11 sharp peak around $\mathrm{t}=0$ is thus the electronic response of the metal film. As the sample is heated 12 it reflects light differently and a step is detected between $t<0$ and $t>0$. This is the thermal response of the sample which slowly decreases as the sample cools down. The acoustic contribution is clearly visible here as a series of sharp signals about every 100 ps superimposed to the thermal decrease. Each of them is an acoustic echo detected at the WTi surface and corresponds to a certain number of round-trips in the WTi film. From the precise time-delay and from the sound velocity of WTi $(5350 \mathrm{~m} / \mathrm{s})$ the thickness is deduced. As visible in Fig.2, sample WTi-2 is found to be slightly thicker than others (about 5\%).

From the same data, the amplitude of the successive echoes can be analyzed to extract the acoustic reflection coefficient. The acoustic reflection coefficient is obtained through the exponential decay of the successive echoes. In the present case the reflection coefficient is obtained using the 3 first echoes.

APiC performs a very local measurement as the laser spot size is in the range $1-2 \mu \mathrm{m}$. To have a more global picture of each sample, it is reproduced at more than 500 points along the sample surface, but only at unbuckled places. This way a statistic is produced of both film thickness 
1 and reflection coefficient. Mean value and standard deviation of thickness and reflection

2 coefficient are given in Table 1.

3 If the film thickness is found not to vary from one point to another (deviation less than $2 \mathrm{~nm}$

4 i.e. less than $0.8 \%$ ), significant variations are observed on the reflection coefficient (from 7 to

5 14\%). This conclusion is more visible in Fig. 3 where the distribution of the reflection

6 coefficient is compared for the three samples. Sample WTi-1 presents a sharp distribution

7 centered around a quite high value (0.55). Sample WTi-2 presents a slightly larger distribution

8 centered around a lower value (0.53). That suggests a better adhesion compared to WTi- 1 . The

9 most interesting result is obtained on sample WTi-3 on which a very large distribution is

10 obtained. That corresponds to the combination of two distributions: one is centered around low

11 values (typ. 0.44) and a second centered around 0.52. From that we suspect that sample WTi-3

12 presents various places along its surface, some of them being well adherent to the substrate and

13 others comparable to other samples.

\subsection{Correlation between buckles analysis and APiC}

16 We now confront the two techniques results. This is done graphically in Fig.4 where the 17 adhesion energy measured using telephone cord buckles is plotted as a function of the reflection coefficient measured by APiC. The mean values are well-aligned along a line that represents the expected tendency: as explained before, the higher the adhesion energy is, the lower the acoustic reflection is expected to be at the interface.

21 Error bars indicate the deviations obtained using both techniques. It's important to note that an error here does not only corresponds to a measurement error but also the variation of the measured quantity along the surface. This is true for both techniques. For buckles analysis, more than 30 defects are analyzed per sample to extract the adhesion energy. For APiC, reflection coefficient is measured at various places at the sample surface. That way two 
1 contrasted regions from the adhesion point of view have been identified on sample WTi-3 which

2 gives a large deviation and error bar. But an important difference between both techniques is

3 that to extract adhesion energy from buckles, the zone must have delaminated there. At a good

4 place, where no delamination occurs, no defect is visible and adhesion energy cannot be

5 extracted following the Hutshinson and Suo method. On the contrary, APiC is applied where

6 the film is still adherent to the substrate and can thus probe well and poorly bonded regions.

7 For that reason, the buckle technique cannot confirm the well bonded region identified on 8 sample WTi-3.

9 In order to determine if such a place is or not a perfect bonded zone, one may compare the reflection coefficient to the theoretical value expected for a perfect WTi/Si interface. One notes

11 that measured reflection coefficients are significantly lower than expected from Eq. (4). This is

12 due to acoustic attenuation that affects the strain pulse amplitude during its propagation in the

13 WTi layer. The role of attenuation is confirmed by the broadening of the echo as its number

14 increases as attenuation preferably affects the high frequency content of the acoustic pulse.

15 Echo amplitude thus decreases for two main mechanism: transmission of acoustic energy to the

16 substrate at the interface WTi/Si and attenuation during propagation in WTi. Both effects must

17 be considered in a numerical modeling of the acoustic signal to compare quantitatively the measured reflection coefficient to the theoretical value. Doing that for WTi on Si and assuming a standard attenuation value for a metal (exact attenuation in the WTi alloy is not perfectly known), one shows that the reflection coefficient must be corrected by a factor 1.3 to decorrelate

21 the attenuation effect. A reflection coefficient of $0.43 \pm 0.05$ then corresponds to reflection 22 coefficient of $0.56 \pm 0.06$, a value close to the theoretical value (0.61) that supports a perfect 23 bonding there.

\section{Conclusion}


1 We presented a comparative study between two much different techniques able to test adhesion

2 of a thin film on its substrate. First adhesion energy is deduced from an analysis of telephone

3 cord buckle defects that appear spontaneously at the sample surface as the metal film is highly

4 stressed. Second, we use ultra-high acoustic waves emitted and detected by femtosecond laser

5 to measure their reflection at the concerned interface. An excellent correlation is obtained

6 between results obtained on a series of three similar samples. This work confirms that acoustic

7 waves may provide an alternative approach to measure the adhesion of thin films. The APiC

8 technique on which such acoustic measurements are based, is a full optical measurement that

9 means with no contact and no destruction of the sample. One may also point that its time-

10 resolved character let it identify the successive interfaces when the layer is stacked in a complex

11 ensemble. As demonstrated here, the APiC technique is very local, the zone to be tested being

12 the focused laser spot size. Thanks to that, adhesion can be compared from one place to another.

13 As shown here, APiC can also access to adhesion at places where no defect exists. An anomaly

14 on acoustic reflection can be detected well before a delamination occurs. 


\section{$1 \quad$ References}

2 [1] V. K. Khanna, J. Phys. D: Appl. Phys. 44 (2011) 034004.

3 [2] Buchwalter L. P., J. Adhes. 72 (2000) 269.

4

[3] Van Driel W. D., van Gils M. A. J., van Silfhout R. B. R. and Zhang G. Q., Microelectron. Reliab. 45 (2005) 1633.

[4] Gerberich W. W. and Cordill M. J., Rep. Prog. Phys. 69 (2006) 2157.

[5] K.L. Mittal in Adhesion Measurement of Films and Coatings, Ed. VSP, Utrecht, The Netherland 1995.

[6] Robert Lacombe, Adhesion Measurement Methods: Theory and Practice, CRC Press (2006).

[7] M.J. Cordill, D.F. Bahr, N.R. Moody, W.W. Gerberich, Mater. Sci. Eng. A. 443 (2007) $150-155$

[8] T. R. Hull, J. S. Colligon, and A. E. Hill, Vacuum 37 (1987) 327.

[9] D. S. Rickerby, Surf. Coat. Tech. 36 (1988) 541.

[10] S. Roy, E. Darque-Ceretti, E. Felder, F. Raynal, I. Bispo, Thin Solid Films 518 (2010) 3859.

[11] M. Lane, E. G. Liniger, and J. R. Lloyd, J. Appl. Phys. 93, 1417 (2003).

[12] M.W. Moon, H.M. Jensen, J.W. Hutchinson, K.H. Oh, A.G. Evans, J. Mech. Phys. Solids. 50 (2002) 2355-2377.

[13] A. Kleinbichler, J. Zechner, M.J. Cordill, Microelectron. Eng. 167 (2017) 63-68.

[14] S.Y. Grachev, A. Mehlich, J.-D. Kamminga, E. Barthel, E. Søndergård, Thin Solid Films. 518 (2010) 6052-6054.

[15] I. Kondo, O. Takenaka, T. Kamiya, K. Hayakama, and A. Kinbara, J. Vac. Sci. Technol. A 12 (1994) 169.

[16] D. B. Marshall, and A. G. Evans, J. Appl. Phys. 10 (1984) 2632. 
1 [17] M. D. Kriese, N. R. Moody, and W. W. Gerberich, J. Mater. Res., 14 (1999) 3007.

2 [18] A. Lassnig, B. Putz, S. Hirn, D.M. Többens, C. Mitterer, M.J. Cordill, Mater. Des. $200(2021) 109451$.

4 [19] C. Thomsen, H. T. Grahn, H. J. Maris, J. Tauc, Phys. Rev. B 34 (1986) 4129.

5 [20] H.T. Grahn, H.J. Maris, J. Tauc, IEEE Journal of Quantum Physics 25 (1989) 2562.

6 [21] A. Devos, R. Cote, G. Caruyer, A. Lefebvre, Appl. Phys. Lett. 86 (2005) 211903.

7 [22] A. Devos and P. Emery, Surface and Coatings Technology 352 (2018) 406.

8 [23] A. Devos, Ultrasonics 56 (2015) 90.

9 [24] J.W. Hutchinson, Z. Suo, Adv. Appl. Mech. 29 (1992) 63.

[25] A. Kleinbichler, M.J. Pfeifenberger, J. Zechner, S. Wöhlert, M.J. Cordill, Mater. Des. $11 \quad 155(2018) 203$.

12 [26] H. Li \& J.J. Vlassak, J. Mat. Res. 24 (2009) 1114-1126.

13 [27] G. Gioia and M. Ortiz, Acta Metallurgica Vol. 46 (1998) 169-175.

14 [28] J.-Y. Faou, G. Parry, S. Grachev, E. Barthel, J. Mech. Phys. Solids 75 (2015) 93-103.

15 [29] A. Devos, R. Cote, Phys. Rev. B 70(12) (2004) 125208.

16 [30] Chameleon Ultra II from Coherent Inc., Santa Clare, CA 95054.

17 [31] A. Kleinbichler, J. Todt, J. Zechner, S. Wöhlert, D.M. Többens, M.J. Cordill, Surf. $18 \quad$ Coatings Technol. 332 (2017) 376.

19 [32] A. Lassnig, B. Putz, S. Hirn, D.M. Többens, C. Mitterer, M.J. Cordill, Mater. Des. 20 $200(2021) 109451$. 


\section{Figure captions}

3 Fig. 1. Representative CLSM height images of three WTi films: (a) WTi-1, (b) WTi-2, and (c)

4 WTi-3. (d) Example of buckle measurements, $\delta$ and 2b, of the white line marked in (b).

5 Fig. 1. Transient response of the 3 WTi samples sputtered on a Si substrate. A series of short

6 acoustic echoes is easily detected. From that we extract the film thickness and the acoustic 7 reflection coefficient at the interface between WTi and Si.

8 Fig. 2. Statistics of the reflection coefficient (absolute value) measured on each WTi sample at $9 \quad$ more than 500 points.

10 Fig. 3. Correlation between adhesion energy measured through buckles analysis and acoustic 11 reflection coefficient measured using picosecond acoustics. The dash line shows the expected tendency for a perfect correlation, the higher adhesion energy is the lower the reflection coefficient is expected to be. 


\section{TABLE 1}

3 Table I: Summary of buckle dimensions, evaluated buckle stress and adhesion energies using 4 the spontaneous telephone cord buckles and a thicknesss of $250 \mathrm{~nm}$. Additionally, the measured 5 thicknesses and the acoustic reflection coefficient using APiC.

6

\begin{tabular}{|c|c|c|c|c|c|c|}
\hline Sample & $\begin{array}{c}\text { Ave. Half } \\
\text { buckle } \\
\text { width, b } \\
(\mu \mathrm{m})\end{array}$ & $\begin{array}{c}\text { Ave. } \\
\text { Buckle } \\
\text { Height, } \delta \\
(\mu \mathrm{m})\end{array}$ & $\begin{array}{c}\text { Buckle } \\
\text { Stress, } \sigma_{b} \\
\text { (MPa) }\end{array}$ & $\begin{array}{c}\text { Mixed } \\
\text { Mode } \\
\text { Adhesion } \\
\text { Energy, } \\
\Gamma(\Psi) \\
\mathbf{J m}^{-2}\end{array}$ & $\begin{array}{c}\text { Thickness } \\
\text { from APiC, } \\
\text { h } \\
(\mathbf{n m})\end{array}$ & $\begin{array}{l}\text { Reflection } \\
\text { Coefficient }\end{array}$ \\
\hline WTi-1 & $18.5 \pm 2.5$ & $1.93 \pm 0.3$ & $55.6 \pm 14.5$ & $2.23 \pm 0.56$ & $256.8 \pm 2.0$ & $0.55 \pm 0.04$ \\
\hline WTi-2 & $20.5 \pm 2.1$ & $2.22 \pm 0.2$ & $43.1 \pm 09.0$ & $2.35 \pm 0.18$ & $270.2 \pm 1.8$ & $0.53 \pm 0.05$ \\
\hline WTi-3 & $15.4 \pm 1.8$ & $1.70 \pm 0.2$ & $79.7 \pm 20.1$ & $2.84 \pm 0.53$ & $259.5 \pm 1.4$ & $0.49 \pm 0.07$ \\
\hline
\end{tabular}


FIGURE 1

2

3
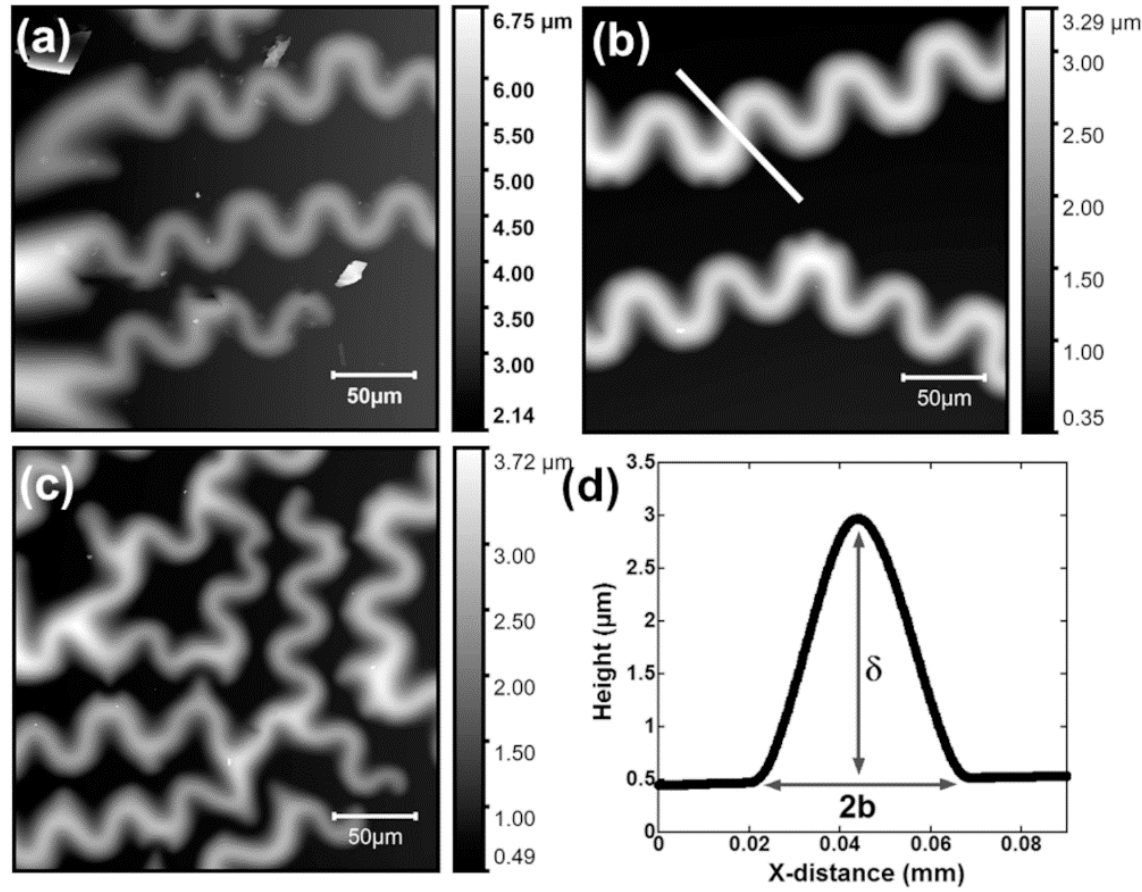

6 Fig. 1. Representative CLSM height images of three WTi films: (a) WTi-1, (b) WTi-2, and (c)

7 WTi-3. (d) Example of buckle measurements, $\delta$ and 2b, of the white line marked in (b). 


\section{FIGURE 2}

2

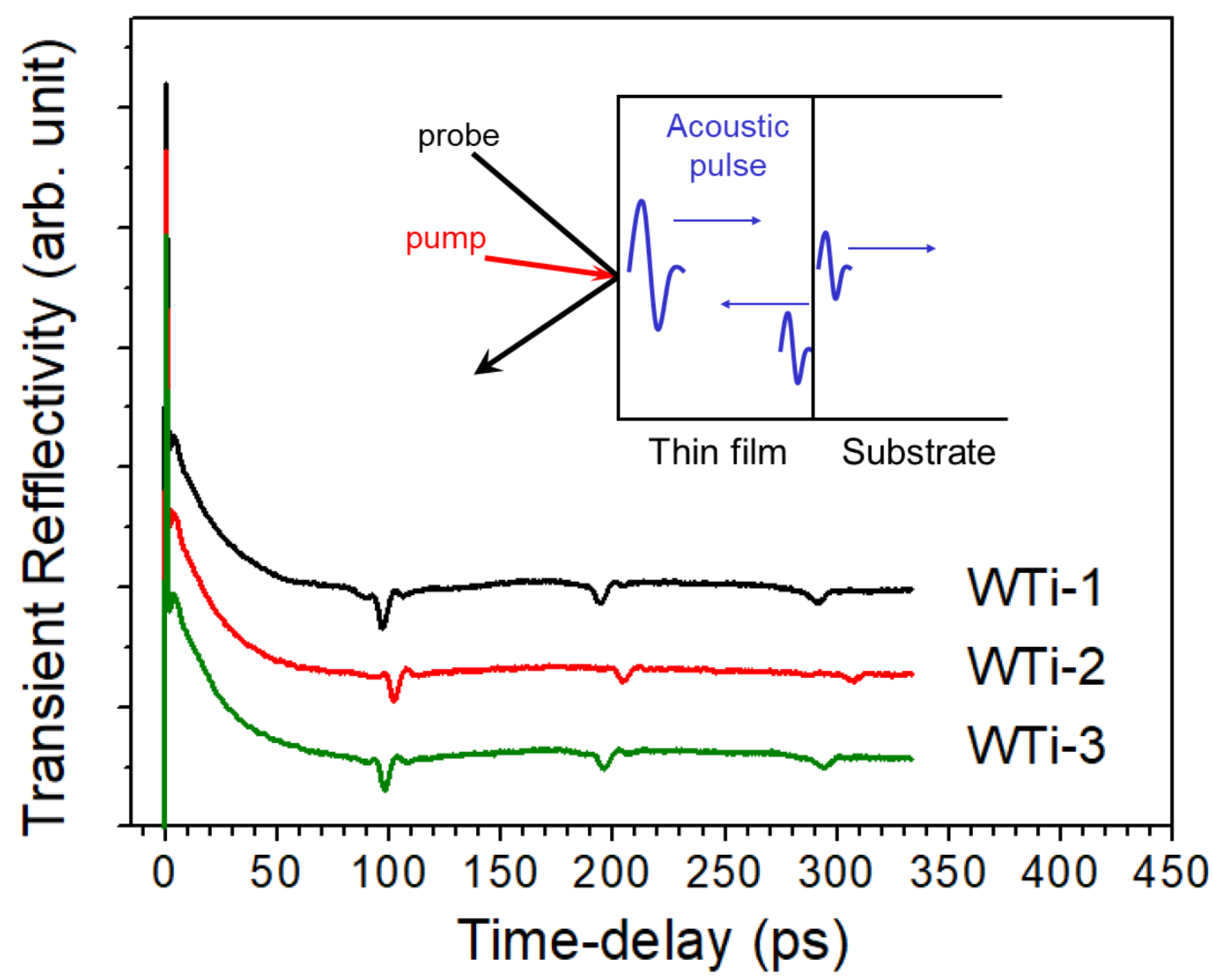

5 Fig. 2 Transient response of the 3 WTi samples sputtered on a Si substrate. A series of short

6 acoustic echoes is easily detected. From that we extract the film thickness and the acoustic

7 reflection coefficient at the interface between WTi and Si. 


\section{FIGURE 3}

2
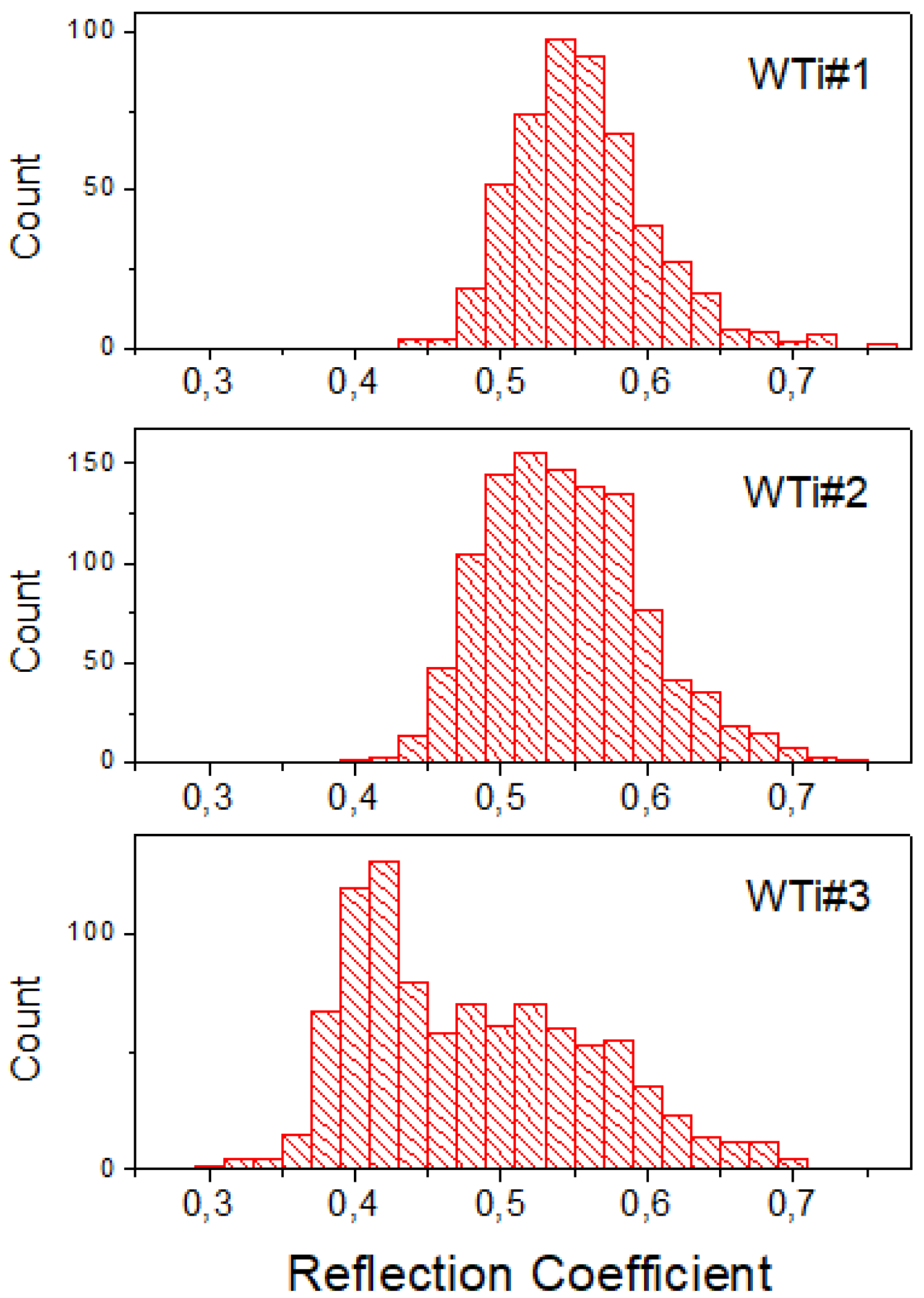

4

5 Fig. 3 Statistics of the reflection coefficient (absolute value) measured on each WTi sample at 6 more than 500 points. 


\section{FIGURE 4}

2

3

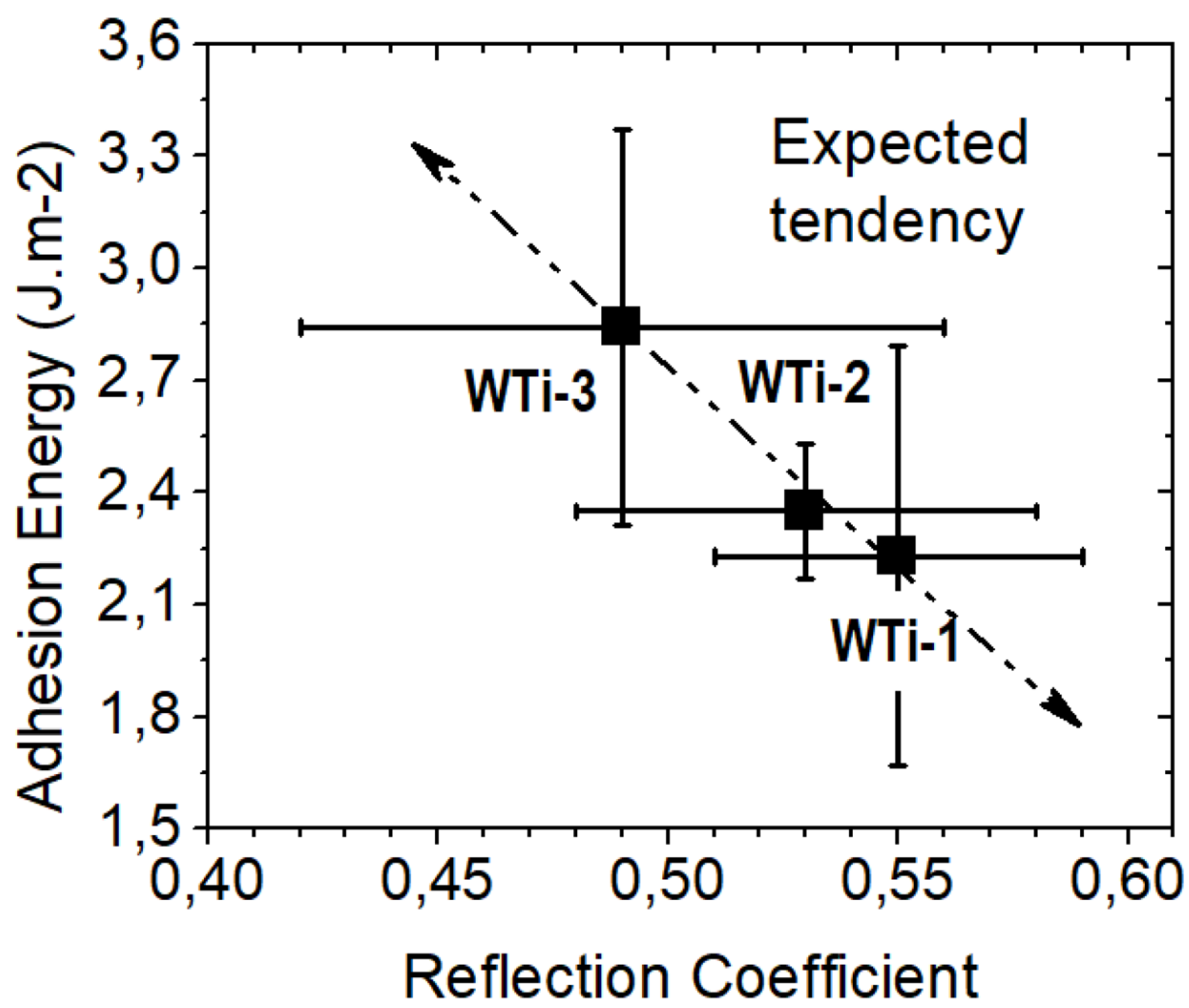

5

6 Fig. 4 Correlation between adhesion energy measured through buckles analysis and acoustic

7 reflection coefficient measured using picosecond acoustics. The dash line shows the expected

8 tendency for a perfect correlation, the higher adhesion energy is the lower the reflection

9 coefficient is expected to be. 